\title{
Impact of surgical site infection on patients' outcome after fixation of tibial plateau fractures: a retrospective multicenter study
}

Ralf Henkelmann ${ }^{1 *}\left(\mathbb{D}\right.$, Richard Glaab², Meinhard Mende ${ }^{3}$, Christopher UII ${ }^{4}$ Philipp-Johannes Braun ${ }^{5}$, Christoph Katthagen ${ }^{6}$, Tobias J Gensior ${ }^{7,8}$, Karl-Heinz Frosch ${ }^{9,10}$, Pierre Hepp ${ }^{1}$ and Committee TRAUMA of the AGA-Society for Arthroscopy and Joint Surgery

\begin{abstract}
Background: Surgical site infection (SSI) occurs in 3-10\% of patients with surgically treated tibial plateau fractures. This study aimed to evaluate the impact of SSI on patients' outcome after fixation of tibial plateau fractures.

Methods: We conducted a retrospective multicenter study in seven participating level I trauma centers between January 2005 and December 2014. All participating centers followed up with patients with SSI. In addition, three centers followed up with patients without SSI as a reference group. Descriptive data and follow-up data with patient-reported outcome scores (Knee Injury and Osteoarthritis Outcome Score [KOOS] and Lysholm knee scoring scale score) were evaluated.
\end{abstract}

Results: In summary, 287 patients (41 with SSI and 246 without SSI; average 50.7 years) with an average follow-up of $75.9 \pm 35.9$ months were included in this study. Patients with SSI had a significantly poorer overall KOOS (KOOS5) $(48.7 \pm 23.2$ versus [vs.] $71.5 \pm 23.5 ; p<0.001)$ and Lysholm knee scoring scale score $(51.4 \pm 24.0$ vs. $71.4 \pm 23.5 ; p<$ 0.001 ) than patients without SSI. This significant difference was also evident in the KOOS subscores for pain, symptoms, activities of daily living (ADL), and quality of life (QoL). SSI remained an important factor in multivariable models after adjusting for potential confounders. Clinically relevant differences in the KOOS5 and KOOS subscores for symptoms, pain, and ADL were found between those with SSI and without SSI even after adjustment. Furthermore, the number of previous diseases, Arbeitsgemeinschaft für Osteosynthesefragen Foundation (AO) C fractures, and compartment syndrome were found to be additional factors related to poor outcome.

Conclusions: Compared to previous studies, validated patient-reported outcome scores demonstrated that the impact of SSI in patients with surgically treated tibial plateau fractures is dramatic, in terms of not only pain and symptoms but also in ADL and QoL, compared to that in patients without SSI.

Keywords: Outcome tibial plateau fracture, surgical site infection, Knee Injury and Osteoarthritis Outcome Score, Lysholm knee scoring scale

\footnotetext{
* Correspondence: ralf.henkelmann@medizin.uni-leipzig.de

'Department of Orthopedics, Trauma and Plastic Surgery, University of Leipzig, Liebigstraße 20, 04103 Leipzig, Germany

Full list of author information is available at the end of the article
}

(c) The Author(s). 2021 Open Access This article is licensed under a Creative Commons Attribution 4.0 International License, which permits use, sharing, adaptation, distribution and reproduction in any medium or format, as long as you give appropriate credit to the original author(s) and the source, provide a link to the Creative Commons licence, and indicate if changes were made. The images or other third party material in this article are included in the article's Creative Commons licence, unless indicated otherwise in a credit line to the material. If material is not included in the article's Creative Commons licence and your intended use is not permitted by statutory regulation or exceeds the permitted use, you will need to obtain permission directly from the copyright holder. To view a copy of this licence, visit http://creativecommons.org/licenses/by/4.0/. The Creative Commons Public Domain Dedication waiver (http://creativecommons.org/publicdomain/zero/1.0/) applies to the data made available in this article, unless otherwise stated in a credit line to the data. 


\section{Background}

The goal of the surgical treatment of tibial plateau fractures (TPFs) is to achieve the best level of mobility and quality of life (QoL) postoperatively. However, the postoperative outcome depends on many factors such as the patient's general health, injury severity with fracture morphology and soft tissue injury, the surgical approach with quality of fracture reduction, and the occurrence of postoperative complications including posttraumatic arthrosis [1-9]. The initial surgical treatment strategy is determined by the fracture morphology, soft tissue damage, concomitant injuries, and patient's general condition. In the early postoperative phase, surgical site infection (SSI) is the most feared complication. Average SSI rates of $\geq 4.5 \%$ have been described [10-12]. SSIs often lead to multiple revision surgeries, delayed recovery, and transient or permanent loss of function in the affected region [13, 14]. Several independent risk factors for SSI have already been identified. Some of these factors may be influenced, offering the potential to reduce the rate of SSI in the future $[11,15]$.

In addition to these findings, little is known to date about the specific outcome after SSI. A systematic review showed that only $44 \%$ of patients have a satisfactory outcome after a deep SSI [16]. However, robust data with validated scores on this issue are still missing. Thus far, the focus of the most studies is to evaluate the general outcome of TPFs [5, 17-19].

Therefore, the present study aimed to evaluate the impact of SSI on outcome after operative treatment of TPF based on patient-reported outcome scores.

\section{Methods}

\section{Study design and setting}

We performed a retrospective multicenter study at seven level I trauma centers in Germany and Switzerland. The study was approved by the leading ethics committee of the University of Leipzig (Reference number: 098/15-ff) and all corresponding ethics committees of the participating centers. An analysis of epidemiologic data from this collective to identify independent risk factors has been previously published [15]. As a next step and for further analysis, all patients with an SSI were invited for follow-up at all seven study centers. Furthermore, in three of the seven study centers, patients without an SSI were additionally invited to undergo follow-up as the reference group.

\section{Patients and eligibility criteria}

All patients who had had surgical treated TPFs at one of the hospitals from January 2005 through December 2014 were identified by querying the hospitals' databases with the International Classification of Disease code for proximal tibia fractures. To avoid inclusion of patients who were improperly coded, those operated on at another hospital, and those who did not meet our inclusion and exclusion criteria, we screened every patient manually.

Inclusion criteria were patient age $>18$ years, primary treatment undergone in one of the participating hospitals, and proximal tibia fractures according to the Arbeitsgemeinschaft für Osteosynthesefragen Foundation/Orthopaedic Trauma Association (AO/OTA) $41 \mathrm{~B}$ or $C$ [20]. Exclusion criteria were previous surgery at the fracture site performed at another hospital, AO $41 \mathrm{~A}$ fractures, and pathological fractures.

\section{Variables, data sources, and measurements}

All variables to be recorded were specified in advance and communicated to all participating centers using a pre-prepared spreadsheet. In addition to the standard parameters (age, sex, etc.), comorbidities were categorized into four groups according to the number of comorbidities: none, 1-3 comorbidities, 4-5 comorbidities, $\geq 6$ comorbidities. Comorbidities included predefined diseases such as diabetes mellitus or hypertension; details have been published elsewhere [15]. The variables diabetes mellitus, nicotine abuse, alcohol/drug abuse as well as immunosuppressive drugs were listed separately at the nominal scale level.

Accompanying injuries to the affected knee joint were classified as none, not relevant (abrasions and soft tissue injuries classified as grade 1 according to the Gustillo and Anderson classification), and relevant (further fractures of the affected extremity and compartment syndrome). Other concomitant injuries were categorized as none, not relevant (hematoma, abrasions, and craniocerebral trauma grade 1), and relevant (fracture to other body region and craniocerebral trauma $>1$ grade). Furthermore, patients with an injury severity score (ISS) > 16 were classified as having polytrauma [21].

The fracture morphology was classified according to the AO/OTA classification [20]. Furthermore, the variables open fracture and compartment syndrome were considered.

SSI was recorded according to the definition proposed by the current protocol of the National Healthcare Safety Network, Centers for Disease Control and Prevention. These definitions are used in the German guideline of the Robert Koch Institute and by the World Health Organization [22].

Outcome was measured using two different patientreported outcome (PRO) scores: the overall Knee Injury and Osteoarthritis Outcome Score (KOOS5) with its corresponding subscores (symptoms, pain, activities of daily living [ADL], function/sports and recreational activities [Sport/Rec], and QoL) and the Lysholm knee scoring scale score [23-25]. For the KOOS5 score (maximum 100), a lower score represented 
more symptoms or pain, greater difficulty performing ADLs and Sport/Rec, and poorer QoL. This rating is also valid for the Lysholm knee scoring scale (maximum 100).

A minimum follow-up was determined at 12 months postoperatively. The follow-up examination of the patient group with SSI was performed at all participating centers. All patients with SSI were contacted and followed up with by telephone or mail. Additional follow-up examination of the reference group with patients without SSI was conducted at three centers.

\section{Bias}

Because of the retrospective study design and the large number of study centers, it is possible that patients with SSI may not have returned to one of the study centers for further treatment. Thus, the number of SSIs may be higher, and the influence of a higher number of patients with SSIs may have an impact on the results.

\section{Statistical methods}

The study cohort was characterized by standard statistics: mean value (standard deviation) for continuous data and number (percent) for categorical data. Patient groups with and without infection were compared using t-test for continuous measurements and chi-square test without correction for cross tables.

We added analyses using general linear models with three objectives: First, we reduced bias by adjusting for confounders by including imbalanced variables in multiple models. Second, these models were used to estimate the effects of known clinical parameters in multiple settings. Third, we separated important variables from negligible variables by simplifying the models. We started with a full model that included SSI, age, sex, body weight, preconditions, smoking and substance abuse, AO classification, and presence of polytrauma, compartment syndrome, concomitant injury, and external fixation. This model was simplified by stepwise backward variable rejection to minimize the Akaike information criterion. The final models were calculated by forcing the remaining variables into the linear model.

All tests were performed two-sided to the significance level $\alpha=0.05$. The analyses were performed with SPSS Statistics version 26 (IBM Corp.) and R software ( $\mathrm{R}$ Core Team).

\section{Results}

\section{Participants}

Between January 2005 and December 2014, 2106 patients were included in the overall study, including 94 patients with SSI, which corresponds to a rate of $4.5 \%$.

Of those 94 patients, 41 could be evaluated according to the study protocol $(43.6 \%)$. As the reference group, 246 patients without SSI with follow-up data were included from three centers $(37.0 \%)$. In summary, 287 patients with an average follow-up of $75.9 \pm 35.9$ months (range, 14-146 months) were included in this study (Fig. 1). Patients with SSI had a mean follow-up of $70.7 \pm 39.0$ months (range, 14-140 months), and patients without SSI had a mean followup of $78.9 \pm 35.4$ months (range, 20-146 months), with no significant difference between the groups $(p=0.3)$.

\section{Descriptive data}

Basic demographic data for the collective and the two subgroups (patients with SSI and those without SSI) are presented in Tables 1 and 2. Patients in the overall group were on average 50.7 years of age, had a body mass index (BMI) of $26.8 \mathrm{~kg} / \mathrm{m}^{2}$, and a percentage of women of $49.1 \%$. There was no significant difference between the groups in terms of age, the presence of diabetes mellitus, BMI, and comorbidities. However, there was a significant difference in body weight, sex, and smoking and drug abuse between the groups (Table 1).

There was a significantly higher proportion of $\mathrm{C}$ fractures in the SSI group than in the non-SSI group. Additionally, the SSI group showed a significantly more complex fracture morphology, had significantly more patients with polytrauma or a relevant concomitant injury to the affected knee joint or other body region, and had significantly more open fractures or compartment syndrome than the non-SSI group (Table 2).

Regarding surgical treatment, an external fixator was applied significantly more frequently in the SSI group than in the non-SSI group. A list of the primary surgical procedures in both groups and in the overall population is shown in Table 3.

\section{Outcome data}

Compared to patients without SSI, those with SSI had a significantly poorer outcome based on the KOOS5 score $(48.7 \pm 23.2$ versus [vs.] $71.5 \pm 23.5)$ and Lysholm knee scoring scale score $(51.4 \pm 24.0$ vs. $71.4 \pm 23.5)$ (Fig. 2; Table 4). Significant differences between the SSI and non-SSI groups were also evident in the KOOS subscores for pain $(57.9 \pm 22.9$ vs. $75.0 \pm 22.3)$, symptoms $(54.5 \pm 28.8$ vs. $75.4 \pm 23.4)$, ADL $(48.8 \pm 27.5$ vs. $80.5 \pm$ $22.6)$, and QOL ( $37.8 \pm 31.5$ vs. $56.4 \pm 30.2)$. For Sports/ Rec, the KOOS5 subscore was not significantly different between the groups $(36.9 \pm 37.1$ vs. $41.0 \pm 35.7)$ (Fig. 2; Table 4). Furthermore, the Lysholm knee scoring scale score differed significantly between the groups (51.4 \pm 24.0 vs. $71.4 \pm 23.5, p=0.001$ ). 


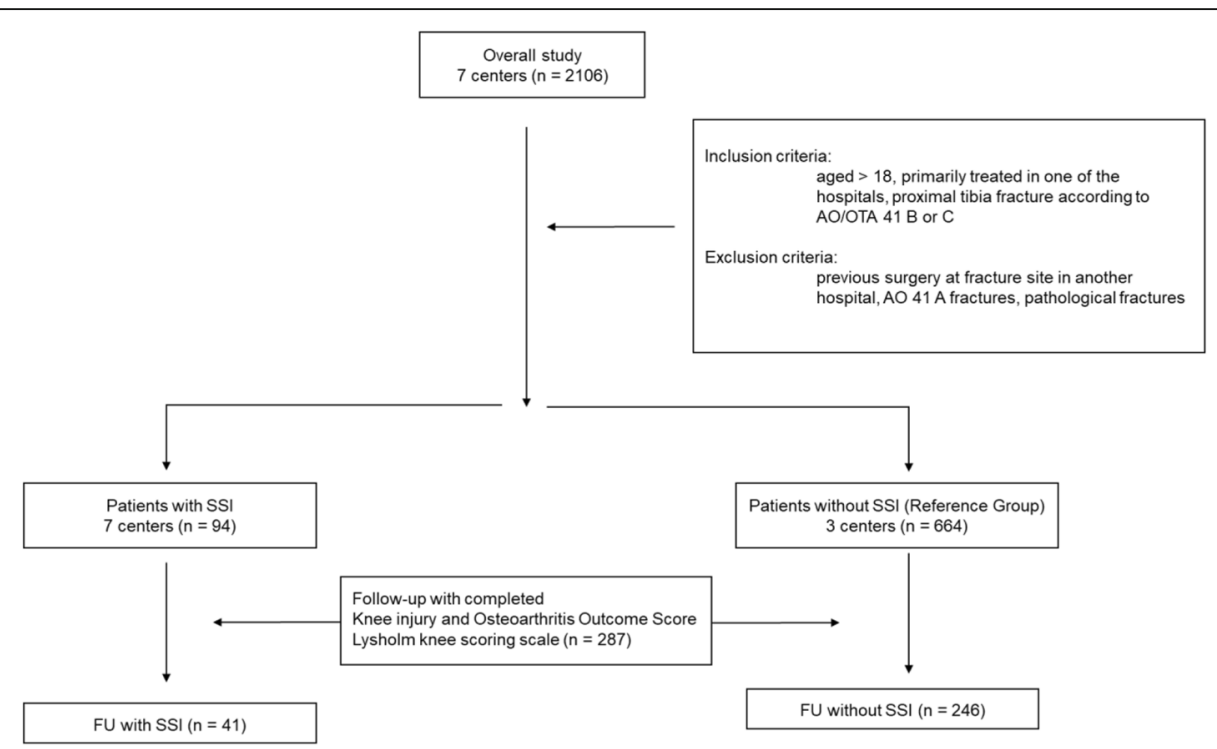

Fig. 1 Flow diagram showing patient selection from different centers. FU, follow-up; SSI, surgical site infection; AO, Arbeitsgemeinschaft für Osteosynthesefragen Foundation; OTA, Orthopaedic Trauma Association

\section{Multivariable models}

SSI remained an important risk factor in the multivariable models after adjustment for possible confounders. The models estimated clinically relevant mean decreases of the KOOS: 16 for the sum score, 15 for the symptoms subscore, 13 for the pain subscore, and 23 for the ADL subscore. Similarly, SSI was associated with about a 10point decrease in the Lysholm knee scoring scale score. The effects of SSI on the Sport/Rec subscore (3.5 points) and QoL subscore (6.5 points) were much lower that those on the other subscores (Table 5). The lack of SSI in the "best models" for these scales indicates that other covariates are much stronger associated with them.

Nearly all scales were strongly associated with the number of pre-existing conditions with effects up to 30 points. Similarly, AO fracture class $\mathrm{C}$ was associated with a mean decrease of about 10 points. Compartment syndrome was associated with the sum score, pain subscore, ADL subscore, and QoL subscore (about a 10point decrease too). The effect of concomitant injury in

Table 1 Descriptive data of the overall population and the subgroups with and without SSI

\begin{tabular}{|c|c|c|c|c|c|c|c|c|}
\hline & & \multicolumn{2}{|c|}{ SSI group $(n=41)$} & \multicolumn{2}{|c|}{ Non-SSI group $(n=246)$} & \multicolumn{2}{|c|}{ Total $(n=287)$} & \multirow[t]{2}{*}{$p$} \\
\hline & & Mean & SD & Mean & SD & Mean & SD & \\
\hline$\overline{\text { Age }}$ & $y$ & 52.1 & 11.1 & 50.5 & 14.2 & 50.7 & 13.8 & 0.4 \\
\hline Weight & $\mathrm{kg}$ & 85.0 & 18.2 & 78.1 & 18.4 & 79.2 & 18.5 & 0.03 \\
\hline \multirow[t]{2}{*}{$\mathrm{BMI}$} & $\mathrm{kg} / \mathrm{m}^{2}$ & 27.7 & 5.1 & 26.7 & 5.4 & 26.8 & 5.4 & 0.2 \\
\hline & & $\mathbf{n}$ & $\%$ & $\mathbf{n}$ & $\%$ & $\mathrm{n}$ & $\%$ & \\
\hline \multirow[t]{2}{*}{ Sex } & Male & 28 & $68.3 \%$ & 113 & $45.9 \%$ & 141 & $49.1 \%$ & 0.01 \\
\hline & Female & 13 & $31.7 \%$ & 133 & $54.1 \%$ & 146 & $50.9 \%$ & \\
\hline \multirow[t]{4}{*}{ Comorbidities } & None & 20 & $48.8 \%$ & 136 & $55.3 \%$ & 156 & $54.4 \%$ & \\
\hline & $1-3$ & 17 & $41.5 \%$ & 95 & $38.6 \%$ & 112 & $39.0 \%$ & \\
\hline & $4-5$ & 3 & $7.3 \%$ & 4 & $1.6 \%$ & 7 & $2.4 \%$ & \\
\hline & $\geq 6$ & 1 & $2.4 \%$ & 7 & $2.9 \%$ & 8 & $2.8 \%$ & 0.2 \\
\hline Diabetes mellitus & & 5 & $12.2 \%$ & 16 & $6.6 \%$ & 21 & $7.3 \%$ & 0.3 \\
\hline Immunosuppression & & 1 & $2.4 \%$ & 3 & $1.2 \%$ & 4 & $1.4 \%$ & \\
\hline Smoking & & 16 & $39.0 \%$ & 50 & $20.3 \%$ & 66 & $23.0 \%$ & 0.03 \\
\hline Drug abuse & & 7 & $17.1 \%$ & 12 & $4.9 \%$ & 19 & $6.6 \%$ & 0.01 \\
\hline
\end{tabular}

$B M I$ body mass index, SSI surgical site infection, SD standard deviation 
Table 2 Data of the overall population and subgroups with/without SSI concerning fracture morphology and concomitant injuries

\begin{tabular}{|c|c|c|c|c|c|c|c|c|}
\hline & & \multicolumn{2}{|c|}{ SSI group $(n=41)$} & \multicolumn{2}{|c|}{ Non-SSI group $(n=246)$} & \multicolumn{2}{|c|}{ Total $(n=287)$} & \multirow[t]{2}{*}{$p$} \\
\hline & & $n$ & $\%$ & $\mathrm{n}$ & $\%$ & $\mathrm{n}$ & $\%$ & \\
\hline \multirow[t]{2}{*}{ AO category } & $B$ & 8 & 19.5 & 142 & 57.7 & 150 & 52.3 & \multirow[t]{2}{*}{$<0.001$} \\
\hline & C & 33 & 80.5 & 104 & 42.3 & 137 & 47.7 & \\
\hline \multicolumn{9}{|l|}{ AO subcategory } \\
\hline & B1 & 2 & 4.8 & 24 & 9.8 & 26 & 9.1 & \\
\hline & B2 & 1 & 2.4 & 44 & 18.0 & 45 & 15.7 & \\
\hline & B3 & 5 & 12.2 & 74 & 30.3 & 79 & 27.5 & \\
\hline & $\mathrm{C} 1$ & 3 & 7.3 & 18 & 7.4 & 21 & 7.3 & \\
\hline & $C 2$ & 6 & 14.6 & 12 & 4.9 & 18 & 6.3 & \\
\hline & C3 & 24 & 58.5 & 74 & 30.3 & 98 & 34.1 & \\
\hline Concomitant injury of the affected knee & & 22 & 53.6 & 96 & 36.4 & 118 & 41.1 & 0.01 \\
\hline Compartment syndrome & & 16 & 39.0 & 14 & 5.7 & 30 & 10.5 & $<0.001$ \\
\hline Open fracture & & 9 & 22.0 & 7 & 2.9 & 16 & 5.6 & $<0.001$ \\
\hline Concomitant injury of other body region & & 20 & 48.8 & 47 & 19.3 & 67 & 23.3 & $<0.001$ \\
\hline Polytrauma & & 8 & 19.5 & 17 & 7.0 & 25 & 8.7 & 0.01 \\
\hline
\end{tabular}

SSI surgical site infection

some models was small. Body weight (estimated 2-2.5 points per $10 \mathrm{~kg}$ ) was weakly associated with the KOOS subscore for QoL and the Lysholm knee scoring scale score. Finally, an increase by 5 points of the KOOS subscore for pain was associated with external fixation, but this was not significant (Table 5).

\section{Discussion}

In terms of PROs, patients with SSI had a significantly poorer outcome than those without SSI. Even after adjusting for possible confounders, SSI remained an important factor in multivariable models for poor outcome. Previously, it was postulated that regardless of the therapeutic approach, relevant impairments in subjective function of the knee joint are common and are explained by the severity of intraarticular bicondylar fractures with multifragmented parts in combination with injury to the cartilage and intraarticular soft tissue structures [26]. For this reason, in addition to SSI, other important factors that can cause a poor outcome should be considered.

After comparing our results with findings from currently available studies that have used the KOOS and Lysholm knee scoring scale as PROs, it is evident that patients with SSI have an even worse outcome based on the KOOS or Lysholm knee scoring scale score. This is independent of whether a subgroup with poor outcome was defined in these studies due to malalignment, insufficient reduction of the fracture, or any serious complication other than SSI [2, 3, 5-9, 17-19]. For example, Singleton et al. showed that the KOOS worsens depending on the articular congruity after reduction [5]. However, patients with SSI had a significantly worse outcome (KOOS pain subscore, 54.5; KOOS ADL subscore, 48.8; KOOS QoL subscore, 37.8) than the subgroup of patients with $>5 \mathrm{~mm}$ of articular depression (KOOS pain subscore, 69.4; KOOS ADL subscore, 78.1; KOOS QoL subscore, 52.8) in this study. Furthermore, Jansen et al.

Table 3 Surgical procedures of the whole population and the subgroups with and without SSI

\begin{tabular}{|c|c|c|c|c|c|c|}
\hline \multirow[t]{2}{*}{ Surgical procedure } & \multicolumn{2}{|c|}{ SSI group $(n=41)$} & \multicolumn{2}{|c|}{ Non-SSI group $(n=246)$} & \multicolumn{2}{|c|}{ Total $(n=287)$} \\
\hline & $\bar{n}$ & $\%$ & $\bar{n}$ & $\%$ & $\bar{n}$ & $\%$ \\
\hline External fixation & 26 & 63.4 & 55 & 22.6 & 81 & 28.2 \\
\hline Plate & 8 & 19.5 & 69 & 28.3 & 77 & 26.8 \\
\hline Screw & 1 & 2.4 & 28 & 11.5 & 29 & 10.1 \\
\hline Plate and screw & 3 & 7.2 & 75 & 30.8 & 78 & 27.2 \\
\hline Double plate & 3 & 7.2 & 14 & 5.7 & 17 & 5.9 \\
\hline TKA & 0 & 0.0 & 2 & 08 & 2 & 0.7 \\
\hline Other & 0 & 0.0 & 3 & 1.2 & 3 & 1.0 \\
\hline
\end{tabular}

TKA total knee arthroplasty, SSI surgical site infection 

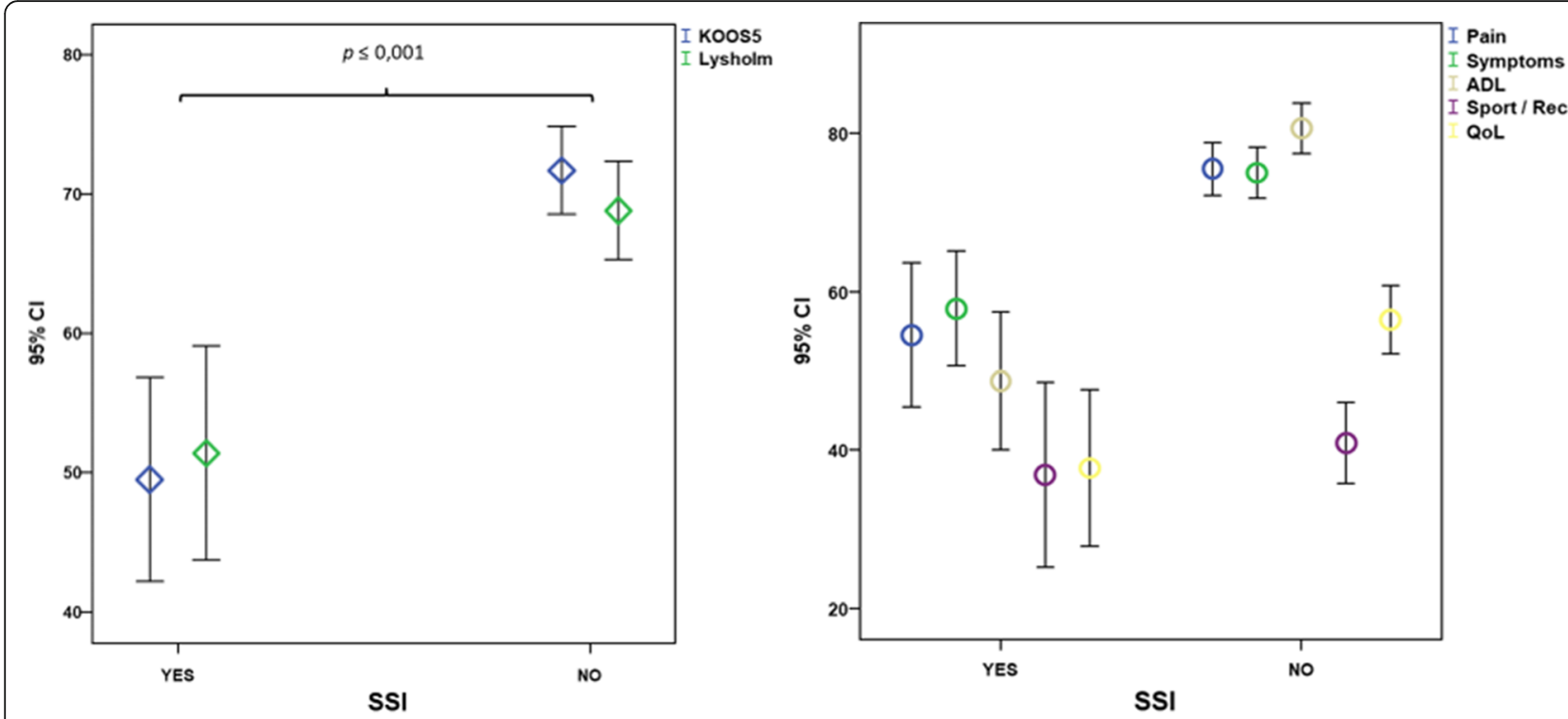

Fig. 2 Comparison of the KOOS5, Lysholm knee scoring scale score, and KOOS subscores in patients with and without SSI. ADL, activities of daily living; Sport/Rec, function/sports and recreational activities; QoL, quality of life; Cl, confidence interval; KOOS, Knee injury and Osteoarthritis Outcome Score; KOOS5, overall Knee injury and Osteoarthritis Outcome Score

evaluated $23 \mathrm{AO} \mathrm{C}$ fractures (follow-up duration, 67 months) with an overall KOOS of 67.84 and Lysholm knee scoring scale score of 66.2; the subgroup with postoperative malalignment had a better outcome (KOOS $58 \pm 14$ ) than the SSI group in our study (KOOS5, $48.7 \pm 23.2$; Lysholm knee scoring scale score, $51.4 \pm$ 24.0) [7]. Larsen et al. included complex bicondylar TPFs $(\mathrm{AO} / \mathrm{OTA} 41 \mathrm{C})$ in their study, and the mean KOOS subscores were as follows: pain, 72.5; symptoms, 62.7; ADL, 75.9; Sport/Rec, 35.4; and QOL, 56.4. Their findings were comparable to our results overall, but their subscores were significantly better than those of our patients with SSI. [2] Additionally, in our study, multivariable analysis showed that AO fracture class $\mathrm{C}$ is associated with a mean decrease of 10 points. In addition to the fracture morphology, the influence of a relevant soft tissue injury in terms of compartment syndrome was shown. Thus far, different effects have been seen on this in other studies [27-29]. The number of previous diseases has a relevant influence on the KOOS subscore for ADL. Although the KOOS is a knee-specific score, the ADL questions refer to activities that that are no longer possible without restrictions in multimorbid patients (e.g., climbing stairs, going shopping, and walking on flat surface).

Finally, our data showed that SSI is responsible for a poor outcome after surgical treatment of a TPF regardless of other risks or influencing factors. These strong results show that in addition to optimal fracture reduction and postoperative management, the avoidance of SSI has the greatest impact on a good outcome in patients with TPF.

\section{Limitations}

The strongest limitation of our study was the retrospective study design. Epidemiological data were complete

Table 4 Outcome based on the KOOS5 subscores and Lysholm knee scoring scale scores

\begin{tabular}{|c|c|c|c|c|c|c|c|c|c|c|c|c|}
\hline \multirow[b]{3}{*}{ KOOS symptoms } & \multicolumn{4}{|c|}{ SSI group $(n=41)$} & \multicolumn{4}{|c|}{ Non-SSI group $(n=246)$} & \multirow[b]{2}{*}{ Diff } & & & \multirow[b]{2}{*}{$p$} \\
\hline & Mean & SD & Min & $\operatorname{Max}$ & Mean & SD & Min & $\operatorname{Max}$ & & \multicolumn{2}{|c|}{$95 \%$ confidence interval } & \\
\hline & 57.9 & 22.9 & 14.3 & 100 & 75.0 & 22.3 & 10.7 & 100 & -17.1 & -25.0 & -9.3 & $<0.001$ \\
\hline KOOS pain & 54.5 & 28.8 & 0.0 & 100 & 75.4 & 23.4 & 2.8 & 100 & -20.9 & -30.5 & -11.2 & $<0.001$ \\
\hline KOOS ADL & 48.8 & 27.5 & 0.0 & 100 & 80.5 & 22.6 & 0.0 & 100 & -31.7 & -40.9 & -22.5 & $<0.001$ \\
\hline KOOS Sport/Rec & 36.9 & 37.1 & 0.0 & 100 & 41.0 & 35.7 & 0.0 & 100 & -4.2 & -16.9 & 8.5 & 0.51 \\
\hline KOOS QoL & 37.8 & 31.5 & 0.0 & 100 & 56.4 & 30.2 & 0.00 & 100 & -18.7 & -29.4 & -7.9 & 0.001 \\
\hline KOOS5 & 48.7 & 23.2 & 5.4 & 97.6 & 71.5 & 21.8 & 7.00 & 100 & -22.8 & -30.7 & -14.9 & $<0.001$ \\
\hline
\end{tabular}

$S D$ standard deviation, $A D L$ activities of daily living, Sport/Rec function/sports and recreational activities, QoL quality of life, min minimum, max maximum, diff difference, KOOS Knee injury and Osteoarthritis Outcome Score, KOOS5 overall Knee injury and Osteoarthritis Outcome Score 
Table 5 Data of multivariate analysis after adjusting for possible confounders

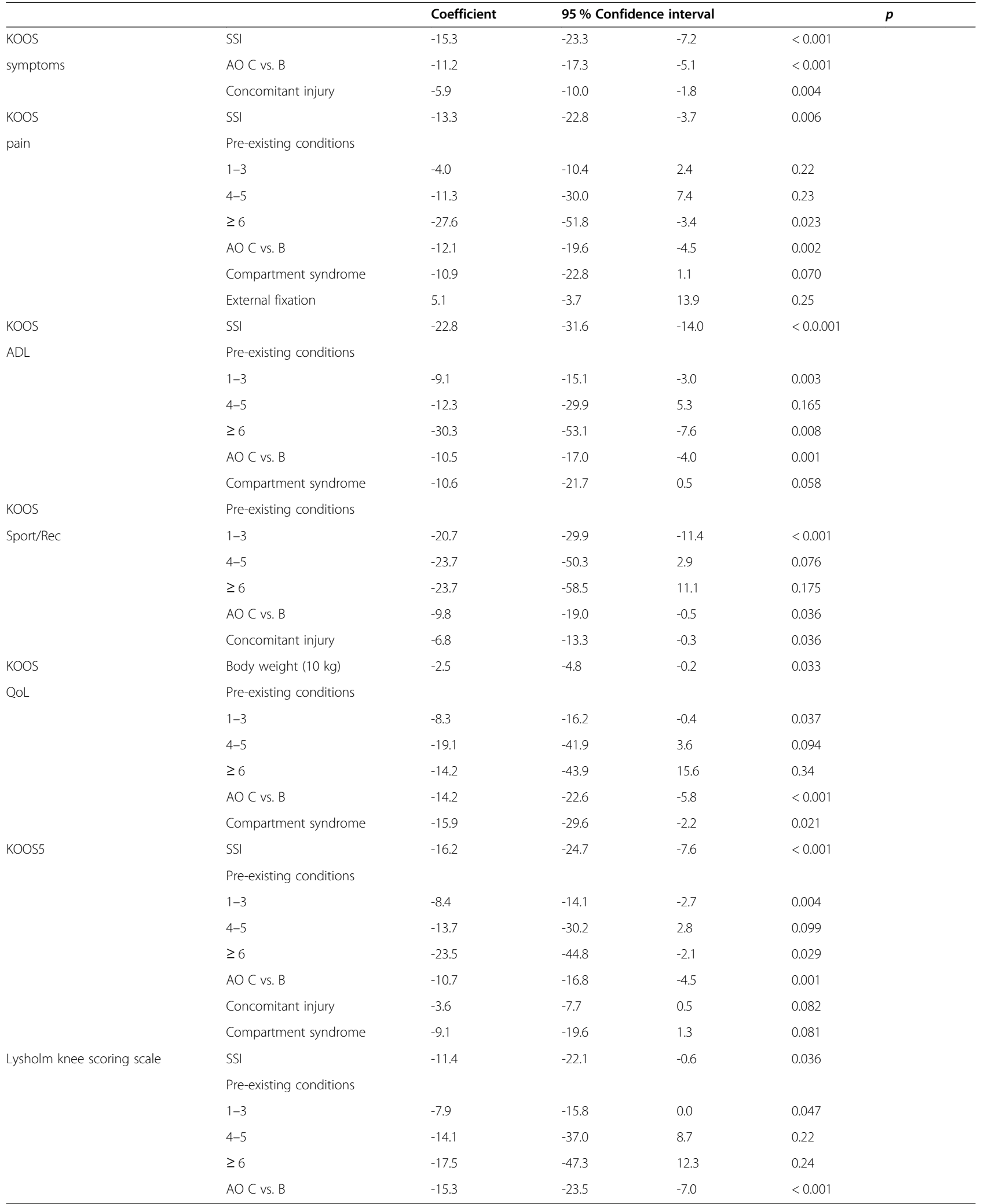


from all participating centers, but only a small number of patients could be reached for follow-up (43.6 and $37.0 \%$ ). Because of this small number of responders, potential bias cannot be excluded. However, in terms of epidemiological data, there was no significant difference between the groups with and without SSI regardless of whether follow-up data were available.

\section{Conclusions}

Compared to previous studies, validated PRO scores demonstrated that the impact of SSI in patients with surgically treated TPFs is dramatic, in terms of not only pain and symptoms but also ADL and QoL, compared to that in patients without SSI.

\section{Abbreviations}

ADL: Activities of daily living; AO/OTA: Arbeitsgemeinschaft für Osteosynthesefragen Foundation/Orthopaedic Trauma Association; BMI: Body mass index; KOOS: Knee injury and Osteoarthritis Outcome Score; KOOS5: Overall Knee injury and Osteoarthritis Outcome Score; ISS: Injury severity score; PRO: Patient-reported outcome; QoL: Quality of life; SD: Standard deviation; Sport/Rec: Sports and recreation; SSI: Surgical site infection; TPF: Tibial plateau fracture

\section{Acknowledgements}

We would like to thank Editage (www.editage.com) for English language editing.

\section{Authors' contributions}

$\mathrm{RH}$ and $\mathrm{PH}$ were responsible for data control and study supervision. The first draft of the manuscript was written by $\mathrm{RH}$ and $\mathrm{PH}$; all authors commented on previous versions of the manuscript. All authors read and approved the final manuscript. RH, TG, CU, PJB, CK, RG, and KHF performed the data acquisition and data control at each trial site and obtained the respective approval of the responsible ethics committee. MM performed data curation, formal analysis, validation, and visualization of the study data, as well as further review and revision of the manuscript. $\mathrm{PH}$ and $\mathrm{RH}$ were responsible for project coordination. All authors have read and approved the manuscript.

\section{Funding}

Open Access funding enabled and organized by Projekt DEAL.

\section{Availability of data and materials}

The datasets used and/or analyzed during the current study are available from the corresponding author on reasonable request.

\section{Declarations}

\section{Ethics approval and consent to participate}

This study was performed in line with the principles of the Declaration of Helsinki. The study was approved by the leading ethics committee of the University of Leipzig (reference number: 098/15-ff) and by the corresponding ethics committees of all participating hospitals. Patients gave their written consent to participate in the study after receiving appropriate information.

\section{Consent for publication}

Not applicable.

\section{Competing interests}

The authors declare that they have no conflict of interest.

\section{Author details}

'Department of Orthopedics, Trauma and Plastic Surgery, University of Leipzig, Liebigstraße 20, 04103 Leipzig, Germany. ${ }^{2}$ Department of Traumatology, Cantonal Hospital Aarau, Tellstrasse 25, 5001 Aarau, Switzerland. ${ }^{3}$ University of Leipzig, Centre for Clinical Trials, Härtlestr. 16/18, 04107 Leipzig, Germany. ${ }^{4}$ Department of General and Trauma Surgery, BG
University Hospital Bergmannsheil, Bürkle de la Camp-Platz 1, 44789 Bochum, Germany. ${ }^{5}$ Department of Trauma and Orthopaedic Surgery, BG Hospital Unfallkrankenhaus Berlin gGmbH, Warener Str. 7, 12683 Berlin, Germany. ${ }^{6}$ Department of Trauma, Hand and Reconstructive Surgery, University Hospital Münster, Waldeyerstraße 1, 48149 Münster, Germany. ${ }^{7}$ Clinic for Arthroscopic Surgery, Sports Traumatology and Sports Medicine, BG Clinic, Großenbaumer Allee 250, 47249 Duisburg, Germany. ${ }^{8}$ Orthopädische Gemeinschaftspraxis Neuss, Breite Str. 96, 41460 Neuss, Germany. ${ }^{9}$ Clinic of Trauma, Hand and Reconstructive Surgery, University Medical Center Hamburg-Eppendorf, Martinistraße 52, 20251 Hamburg, Germany.

${ }^{10}$ Department of Trauma and Reconstructive Surgery, Division of Knee and Shoulder Surgery, Sports Traumatology, Asklepios Klinik St. Georg,

Lohmühlenstraße 5, 20099 Hamburg, Germany.

Received: 11 December 2020 Accepted: 26 May 2021

Published online: 09 June 2021

\section{References}

1. McNamara IR, Smith TO, Shepherd KL, Clark AB, Nielsen DM, Donell S, et al. Surgical fixation methods for tibial plateau fractures. Cochrane Database Syst Rev. 2015:CD009679. https://doi.org/10.1002/14651858.CD009679.pub2.

2. Larsen P, Traerup J, Mikuzis M, Elsoe R. Patient-reported and Functional Outcomes of Bicondylar Tibial Plateau Fractures Managed by Internal Screw Fixation in Combination with An llizarov Fixator: A Case Series of 22 Patients with Long-term Follow-up. Strategies Trauma Limb Reconstr. 2019;14:85-91. https://doi.org/10.5005/jp-journals-10080-1432.

3. Elsoe R, Motahar I, Mahdi F, Larsen P. Presence of magnetic resonance imaging verified soft tissue injuries did not significantly affect the patientreported outcome 12 months following a lateral tibial plateau fracture: A 12-month prospective cohort study of 56 patients. Knee. 2020;27:420-7. https://doi.org/10.1016/j.knee.2020.01.008.

4. Elsoe R, Larsen P. Delayed but favourable outcome of lateral tibial plateau fracture after screw fixation: A 3-year prospective cohort study of 56 patients. Knee. 2021;29:280-90. https://doi.org/10.1016/j.knee.2021.02.015.

5. Singleton N, Sahakian V, Muir D. Outcome After Tibial Plateau Fracture: How Important Is Restoration of Articular Congruity? J Orthop Trauma. 2017;31: 158-63. https://doi.org/10.1097/BOT.0000000000000762.

6. van Dreumel RLM, van Wunnik BPW, Janssen L, Simons PCG, Janzing HMJ. Mid- to long-term functional outcome after open reduction and internal fixation of tibial plateau fractures. Injury. 2015;46:1608-12. https://doi.org/1 0.1016/j.injury.2015.05.035.

7. Jansen H, Frey SP, Doht S, Fehske K, Meffert RH. Medium-term results after complex intra-articular fractures of the tibial plateau. J Orthop Sci. 2013;18: 569-77. https://doi.org/10.1007/s00776-013-0404-3.

8. Rademakers MV, Kerkhoffs GMMJ, Sierevelt IN, Raaymakers ELFB, Marti RK. Operative treatment of 109 tibial plateau fractures: five- to 27-year follow-up results. J Orthop Trauma. 2007;21:5-10. https://doi.org/10.1097/BOT.0b013 e31802c5b51.

9. Reahl GB, Marinos D, O'Hara NN, Howe A, Degani Y, Wise B, et al. Risk Factors for Knee Stiffness Surgery After Tibial Plateau Fracture Fixation. J Orthop Trauma. 2018;32:e339-43. https://doi.org/10.1097/BOT. 0000000000001237.

10. Momaya AM, Hlavacek J, Etier B, Johannesmeyer D, Oladeji LO, Niemeier TE, et al. Risk factors for infection after operative fixation of Tibial plateau fractures. Injury. 2016;47:1501-5. https://doi.org/10.1016/j.injury.2016.04.011.

11. Norris GR, Checketts JX, Scott JT, Vassar M, Norris BL, Giannoudis PV. Prevalence of Deep Surgical Site Infection After Repair of Periarticular Knee Fractures: A Systematic Review and Meta-analysis. JAMA Netw Open. 2019;2: e199951. https://doi.org/10.1001/jamanetworkopen.2019.9951.

12. Ochen Y, Peek J, McTague MF, Weaver MJ, van der Velde D, Houwert RM, et al. Long-term outcomes after open reduction and internal fixation of bicondylar tibial plateau fractures. Injury. 2020;51:1097-102. https://doi.org/1 0.1016/j.injury.2020.03.003.

13. Parkkinen M, Madanat R, Lindahl J, Mäkinen TJ. Risk Factors for Deep Infection Following Plate Fixation of Proximal Tibial Fractures. J Bone Joint Surg Am. 2016;98:1292-7. https://doi.org/10.2106/JBJS.15.00894.

14. Darouiche RO. Treatment of infections associated with surgical implants. N Engl J Med. 2004;350:1422-9. https://doi.org/10.1056/NEJMra035415.

15. Henkelmann R, Frosch KH, Mende M, Gensior TJ, UII C, Braun P-J, et al. Risk factors for deep surgical site infection in patients with operatively treated 
tibial plateau fractures: A retrospective multicenter study. J Orthop Trauma. 2020. https://doi.org/10.1097/BOT.0000000000002011.

16. Henkelmann R, Frosch KH, Glaab R, Lill H, Schoepp C, Seybold D, et al. Infection following fractures of the proximal tibia - a systematic review of incidence and outcome. BMC Musculoskelet Disord. 2017;18:481. https://doi. org/10.1186/s12891-017-1847-z.

17. Timmers TK, van der Ven DJC, Vries LS de, van Olden GDJ. Functional outcome after tibial plateau fracture osteosynthesis: a mean follow-up of 6 years. Knee. 2014;21:1210-5. https://doi.org/10.1016/j.knee.2014.09.011.

18. van den Berg J, Reul M, Nunes Cardozo M, Starovoyt A, Geusens E, Nijs S, et al. Functional outcome of intra-articular tibial plateau fractures: the impact of posterior column fractures. Int Orthop. 2017;41:1865-73. https:// doi.org/10.1007/s00264-017-3566-3.

19. Evangelopoulos D, Chalikias S, Michalos M, Vasilakos D, Pappa E, Zisis K, et al. Medium-Term Results after Surgical Treatment of High-Energy Tibial Plateau Fractures. J Knee Surg. 2019;33:394-8. https://doi.org/10.1055/s-003 9-1677822.

20. Meinberg EG, Agel J, Roberts CS, Karam MD, Kellam JF. Fracture and Dislocation Classification Compendium-2018. J Orthop Trauma. 2018; 32(Suppl 1):1-170. https://doi.org/10.1097/BOT.0000000000001063.

21. Baker SP, O'Neill B, Haddon W, Long WB. The injury severity score: a method for describing patients with multiple injuries and evaluating emergency care. J Trauma. 1974;14:187-96.

22. CDC Definition SSI. http://www.cdc.gov/nhsn/pdfs/pscmanual/ 9pscssicurrent.pdf. Accessed 7 Sep 2018.

23. Kessler S, Lang S, Puhl W, Stöve J. Der Knee Injury and Osteoarthritis Outcome Score-ein Funktionsfragebogen zur Outcome-Messung in der Knieendoprothetik. Z Orthop Ihre Grenzgeb. 2003;141:277-82. https://doi. org/10.1055/s-2003-40083.

24. Roos EM, Roos HP, Lohmander LS, Ekdahl C, Beynnon BD. Knee Injury and Osteoarthritis Outcome Score (KOOS)--development of a self-administered outcome measure. J Orthop Sports Phys Ther. 1998;28:88-96. https://doi. org/10.2519/jospt.1998.28.2.88.

25. Briggs KK, Steadman JR, Hay CJ, Hines SL. Lysholm score and Tegner activity level in individuals with normal knees. Am J Sports Med. 2009;37:898-901. https://doi.org/10.1177/0363546508330149.

26. Ahearn N, Oppy A, Halliday R, Rowett-Harris J, Morris SA, Chesser TJ, et al. The outcome following fixation of bicondylar tibial plateau fractures. Bone Joint J. 2014;96-B:956-62. https://doi.org/10.1302/0301-620X.96B7.32837.

27. Thabet AM, Simson JE, Gerzina C, Dabash S, Adler A, Abdelgawad AA. The impact of acute compartment syndrome on the outcome of tibia plateau fracture. Eur J Orthop Surg Traumatol. 2018;28:85-93. https://doi.org/10.1 007/s00590-017-2017-6.

28. Blair JA, Stoops TK, Doarn MC, Kemper D, Erdogan M, Griffing R, et al. Infection and Nonunion After Fasciotomy for Compartment Syndrome Associated With Tibia Fractures: A Matched Cohort Comparison. J Orthop Trauma. 2016;30:392-6. https://doi.org/10.1097/BOT.0000000000000570.

29. Haller JM, Holt D, Rothberg DL, Kubiak EN, Higgins TF. Does Early versus Delayed Spanning External Fixation Impact Complication Rates for Highenergy Tibial Plateau and Plafond Fractures? Clin Orthop Relat Res. 2016 474:1436-44. https://doi.org/10.1007/s11999-015-4583-4.

\section{Publisher's Note}

Springer Nature remains neutral with regard to jurisdictional claims in published maps and institutional affiliations.

Ready to submit your research? Choose BMC and benefit from:

- fast, convenient online submission

- thorough peer review by experienced researchers in your field

- rapid publication on acceptance

- support for research data, including large and complex data types

- gold Open Access which fosters wider collaboration and increased citations

- maximum visibility for your research: over $100 \mathrm{M}$ website views per year

At BMC, research is always in progress.

Learn more biomedcentral.com/submissions 